\title{
أسلوب ترجمة المجاز إلى التشبيه : دراسة للنصوص القرآنية المترجمة إلى اللغة الملايوية
}

Nasimah Abdullah

Faculty of Islamic Civilization Studies, International Islamic University College of Selangor (KUIS), 44300, Bandar Seri Putra, Selangor, Malaysia. Tel: (60) 0129837495. Email: nasimah@kuis.edu.my

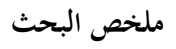

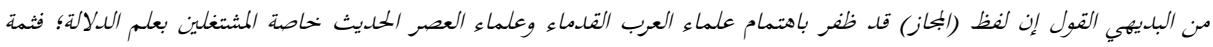

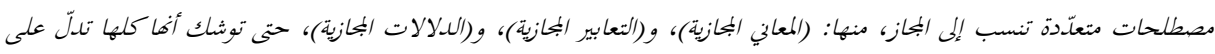

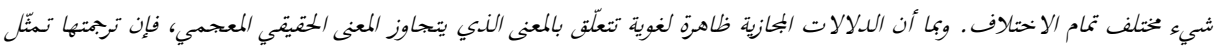

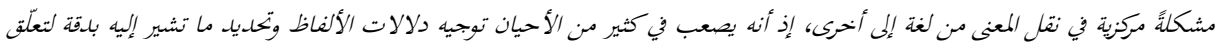

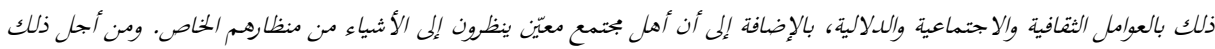

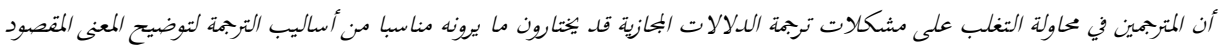

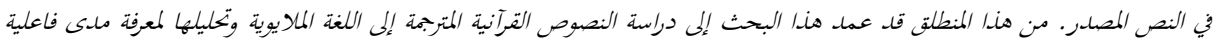

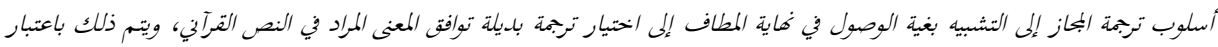

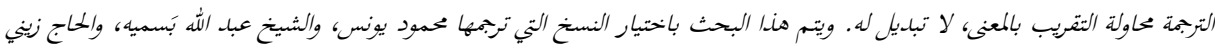

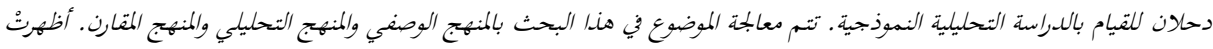

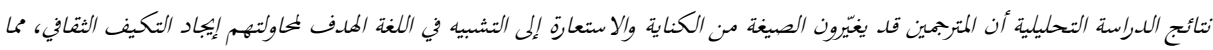

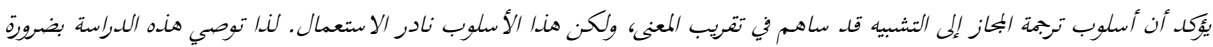

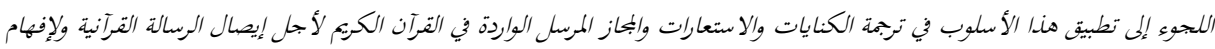

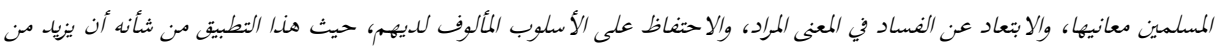

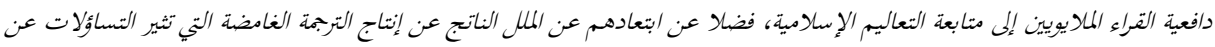
مقصودية الرسالة القرآنية الصحيحة. الكلمات المفتاحية: أسلوب الترجمة، البحاز، التشبيه، اللغة الملايوية

\section{(METHOD OF TRANSLATING METAPHOR INTO SIMILE : A STUDY ON QURANIC TEXTS TRANSLATED INTO MALAY LANGUAGE)}

\begin{abstract}
Obviously the term (البحاز) has been given significant attention by the Arab traditional scholars as well as the modern scholars especially those involved in semantic fields.

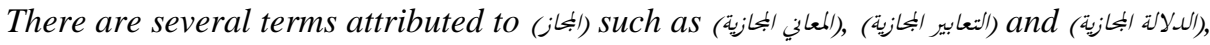
until they are almostly considered as having different concepts. As figurative meaning is a linguistic phenomenon that transcends its literal meaning, its translation is regarded as one of the crucial problems in conveying accurate meaning from one
\end{abstract}




\section{Published by Faculty of Islamic Civilization Studies, KUIS}

language to another. It is often difficult to ensure precise translation for figurative meaning due to its relationship with cultural, social and semantic factors in addition to people of particular community who usually look at things from their own perspective. As a result, the translator will sometimes choose certain translation method in order to overcome the problem of interpreting to clarify the intended meaning of the source text. From this point of view, this paper aims to study Quranic texts translated into Malay language, and then analyze them to discover the effectiveness of the translation method used that is to translate metaphor into simile as well as to suggest a better translation that could attain the nearest connotation intended by the original Arabic text. This study employs descriptive, analytical and comparative methods on selected Quranic translations in Malay language by Mahmoud Younus, Abdullah Basmeih and Zaini Dahlan. The findings show that these translators sometimes change the form of Quranic metonymy and metaphor to simile in the target language as to create a cultural adaptation. This surely confirms that the method of translating metaphor into simile has contributed towards bringing the closest meaning but this method is rarely used. Therefore, this study suggests applying this method in translating Quranic metonymies, metaphors and synecdoches in order to convey the meaning of the Quran clearly and to educate non-Arabic Muslim speakers with the messages of the Quran and its teachings, as well as to avoid from inaccuracy of the intended meaning and to retain the usual method that suits the nature of the target language.

Keywords: Translation method; Metaphor; Simile; Malay Language

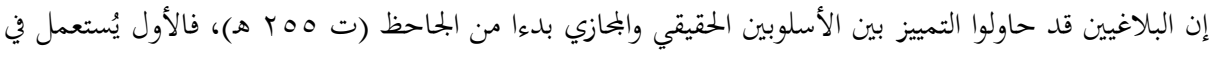

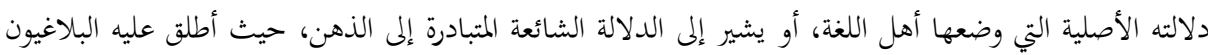

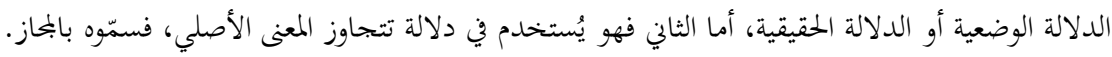

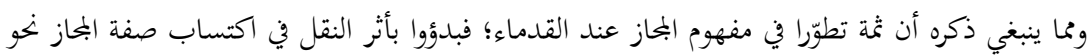

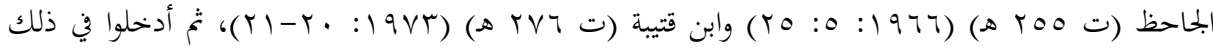

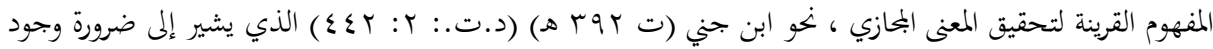

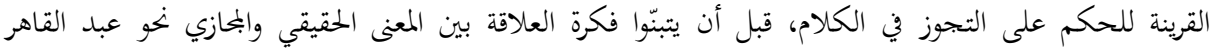

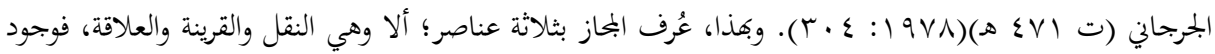

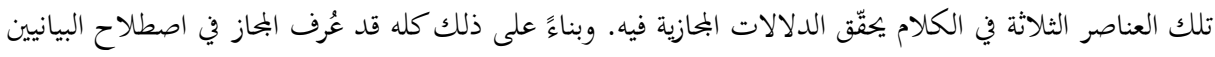

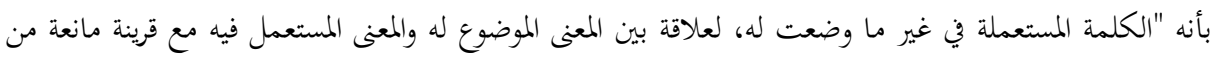

$$
\begin{aligned}
& \text { إرادة المعنى الموضوع له" (لاشين: } 1991 \text { 1: 1ـ 1). }
\end{aligned}
$$




\section{ISSN 0128-116X}

VOL. 2, NO. 2, DEC 2017

وبناء على ما تقدم يمكن أن نقول إن لفظ (المحاز) قد ظفر باهتمام علماء العرب القدماء وعلماء العصر الحديث خحاصة المشتغلين بعلم الدلالة؛ فثمة مصطلحات متعدّدة تنسب إلى البماز، منها: (المعاني البحازية)، و والتعابير

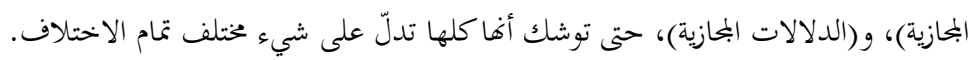

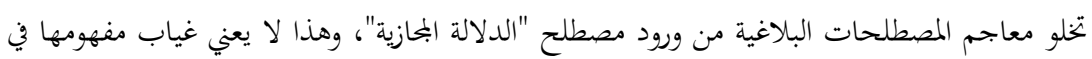
الدراسات البلاغية العربية، بل يشيع مصطلح آخر فيها، وهو "المعنى البمازي"، حيث كان ولا يزال الباحثون يحاولون

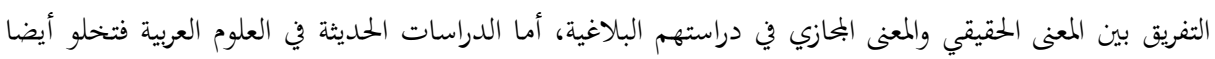

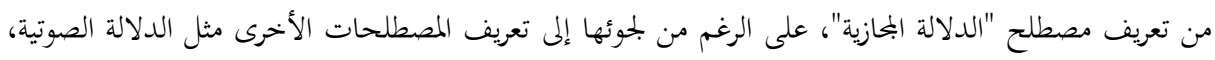

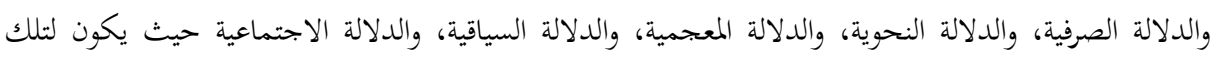

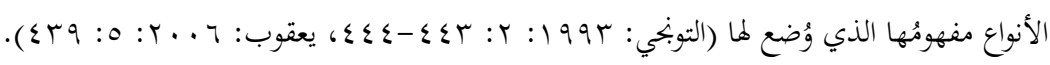

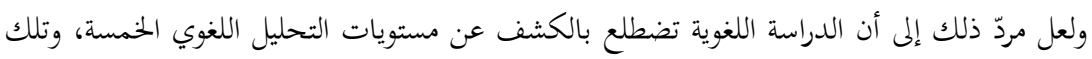

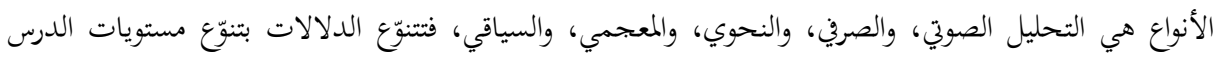

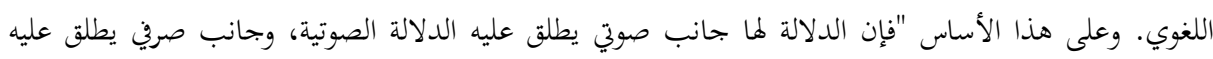

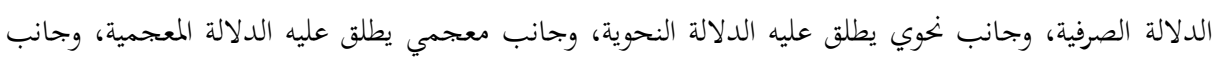

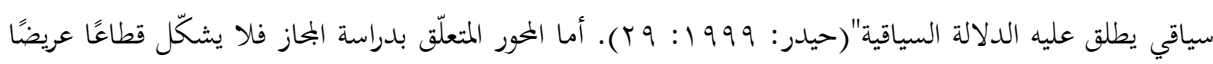
وأساسيا في الدرس اللغوي، فقضية المحاز إذن لا تتمثّل في الجانب اللغوي إلا بنصيب قليل، ولنيل ولذلك غالبا ما يتركها اللغويون في الدراسة البلاغية والأدبية.

فمن الملاحظ أن الاستعمال الشائع في الدراسات البلاغية والقرآنية هو مصطلحا (المعاني المحازية)

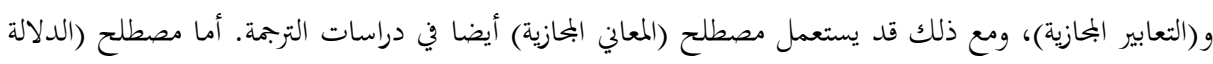

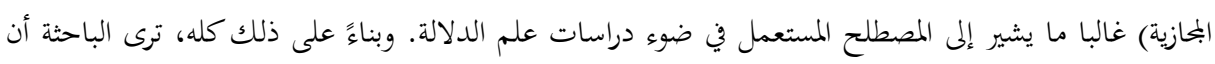
ليس ثمة فرق بين تلك المصطلحات لأنها كلها تومئ إلى البمازات.

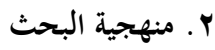

ويبدو جليا أن المترجمين الملايويين للقرآن الكريم - في محاولة التغلب على مشكلات ترجمة الدلالات البحازية القرآنية

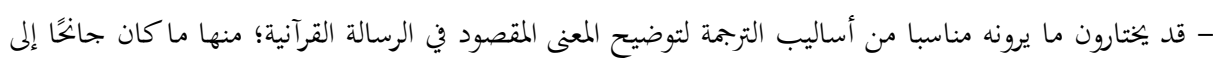

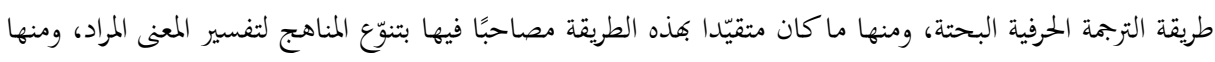

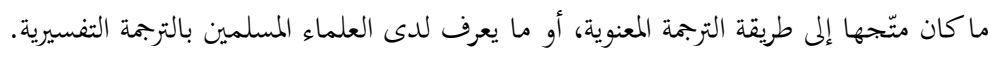
من هذا المنطلق قد عمد هذا البحث إلى دراسة النصوص القرآنية المترجمة إلى اللغة الملايوية وتحليلها

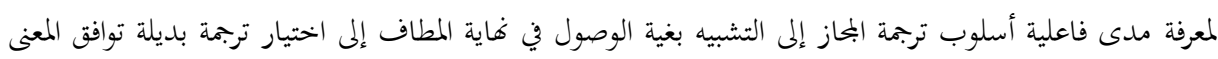

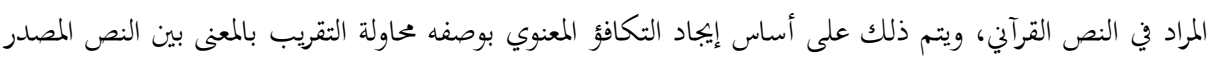

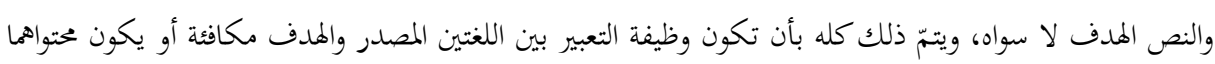

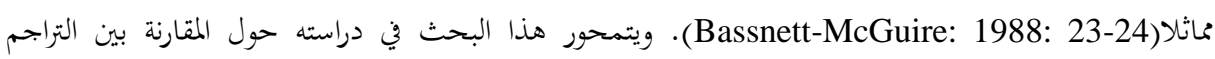


الملايوية الفردية، وتلك التراجم المقصودة هي النسخ التي ترجمها محمود يونس، والشيخ عبد الله بَسميه، والحاج زيني

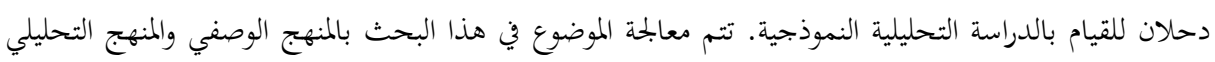
والمنهج المقارن.

\section{ب. - مفهوم الدلالة المجازية}

الدلالة البحازية تعني استعمال التعبيرات لغير معناها الحقيقي خارجا عن الاستعمال المعجمي. فاستعمل الدكتور

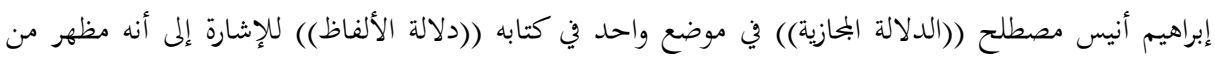

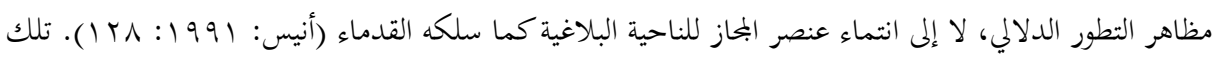

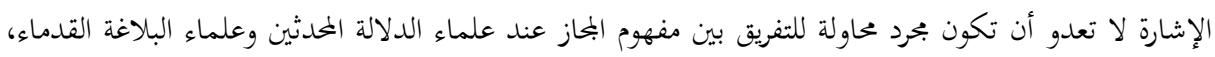
وهي لا تقدم تعريفا للدلالة البمازية على وجهد قاطع.

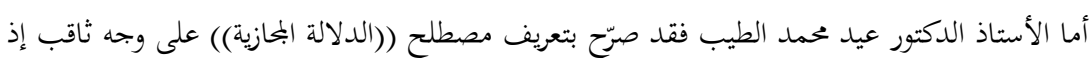
يعرّف هذا المصطلح قائلا: "وتستفاد هذه الدلالة من استخدام اللفظ في غير معناه الوضعي الحقيقي المعجمي

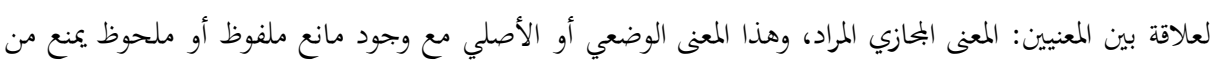

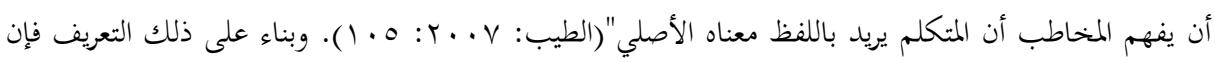

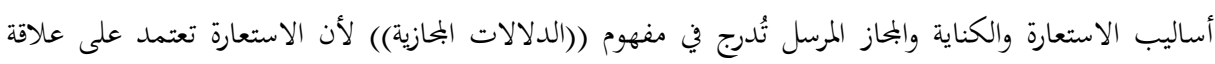

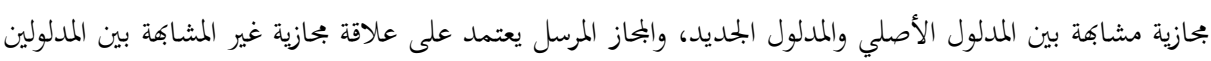

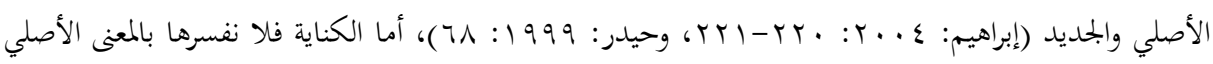

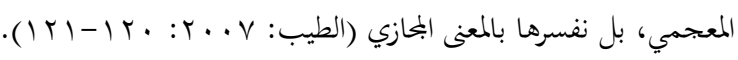

\section{ع. استفادة دراسات الترجمة من علم الدلالة}

يأخذ علم الدلالة بعين الاعتبار القضايا المتعلّقة بالمعنى بمختلف أنواعه ومشكلاته، وهذا المسلك هو ما سلكه

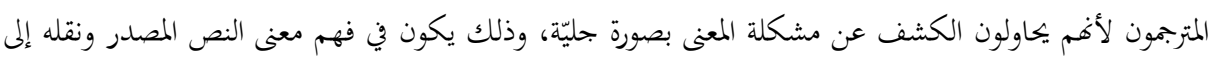
اللغة الهدف نقلاً صحيحًا.

كيف فهم المترجم النص المصدر وفسّره وحلّ رموزه وأزال تعدّديته الدلالية قبل قيامه بنقل ذلك النص

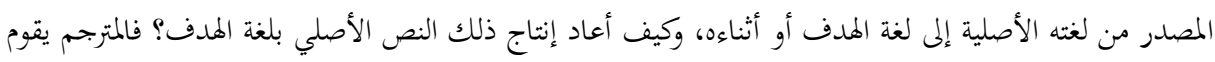

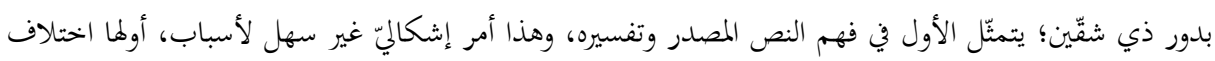

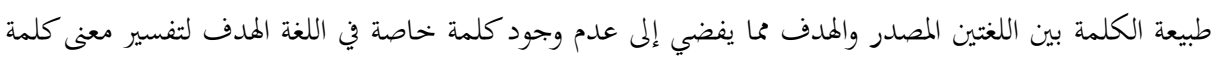

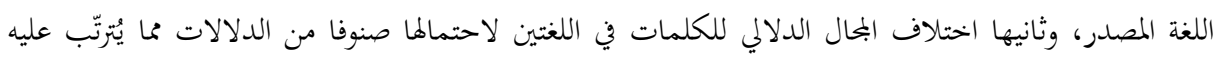

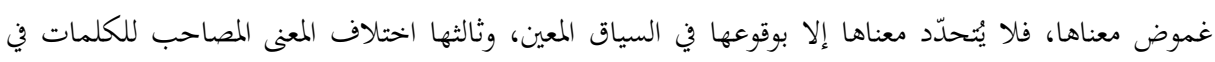

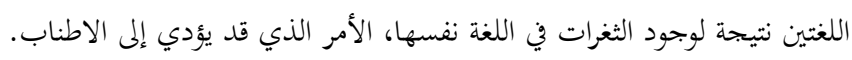


ويتمثّل الشقّ الثاني في إعادة خلق النص بلغة الهدف، وهذه بدورها عملية شديدة التعقيد، إلا أنه لا

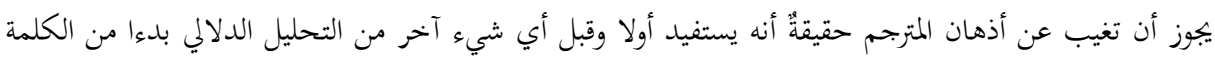

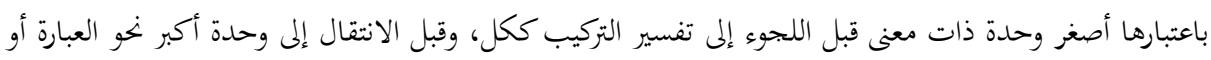

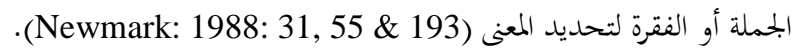

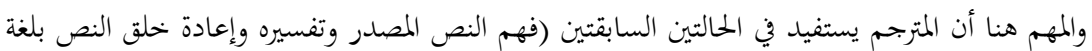

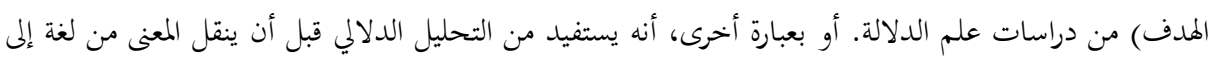
أخرى.

\section{هـ - مشكلات ترجمة الدلالات المجازية}

لا يخفى أن ترجمة المحازات العربية إلى اللغة الملايوية حرفيًّا غالبا ما تفضي إلى اللبس في المعنى أو فساده، ومرد ذلك

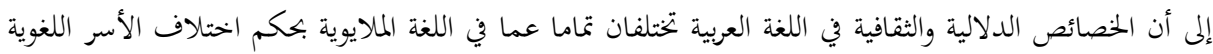
بينهما، الأمر الذي يؤدي إلى التباين في الاستخدامات للألفاظ والتعبيرات والجمل. وبالإضافة إلى ذلك، إن إنهات الصورة الذهنية في البحازات العربية قد تكون غير معروفة لدى بحتمع اللغة الملايوية.

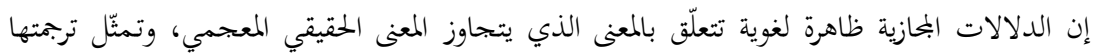

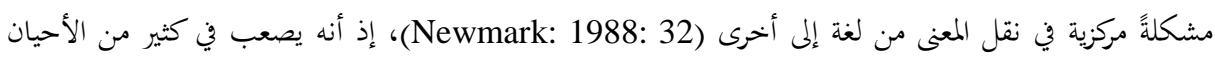

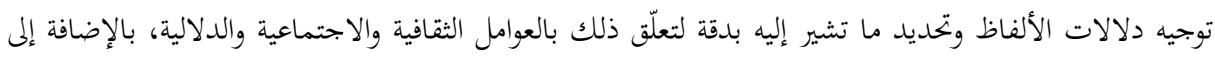

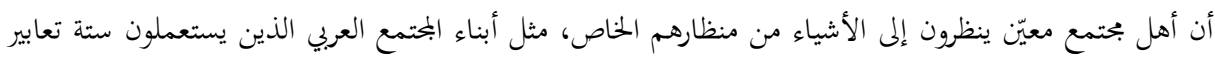

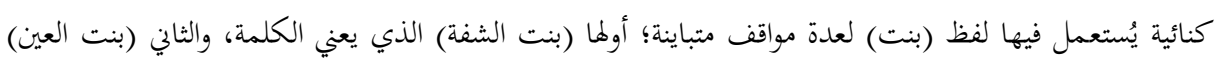

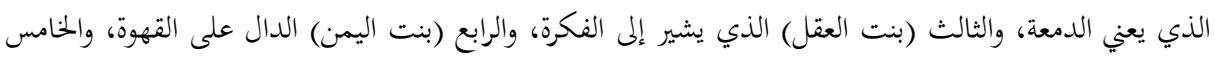
(بنت الأرض) الذي يعني الحصاة، والسادس (بنت اليم) الذي يشير إلى السفينة. وههنا من جماليات اللغة العربية.

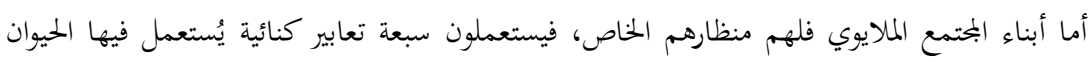

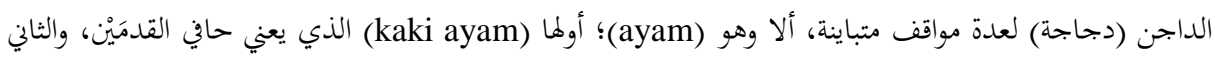

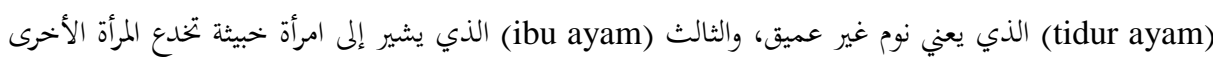

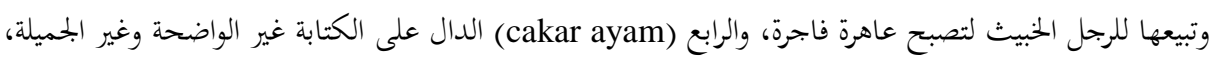

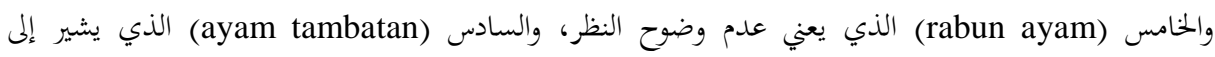

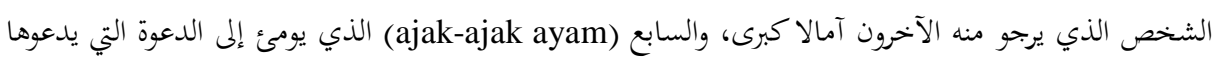

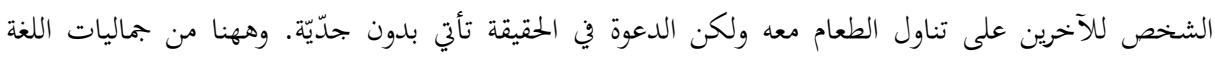

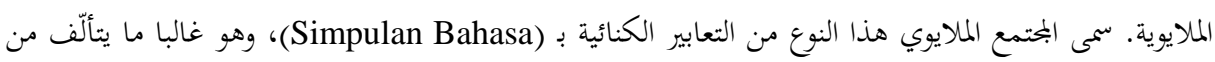
لفظَيْن مركبين متلازمين ويشير إلى معنى مُدْمَج مُمتلئ.

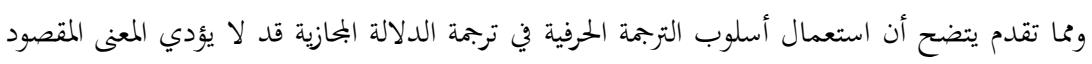
بالضبط لأن المعنى قد لا يتأتى عبر الشكل برمته. ولعل هذا يناسب ما وصفته مارلين قادس روز 


\section{Published by Faculty of Islamic Civilization Studies, KUIS}

Rose: بالترجمة السيئة لاعتماد المترجم على ترجمة الكلمات دون إدراكٍ للمعنى الكلي للنص Gaddis Rose .(1981: 1

في حين أن بعض التراكيب أو العبارات يصلح فيهما تطبيق الترجمة الحرفية، إذ تشير التراكيب والعبارات في اللغة الهدف إلى المعنى المراد في اللغة المصدر. أو بعبارة أخرى، يمكن أن يتحقق المقابل الشكلي عبر الاستبدال

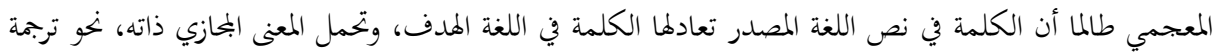
bulan madu gerang dingin

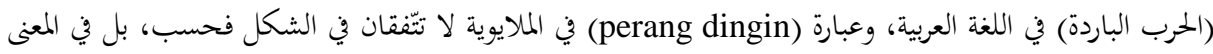

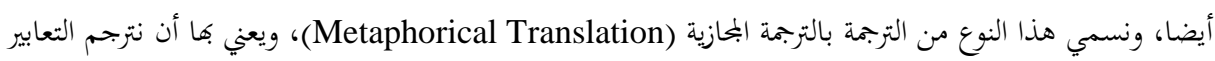

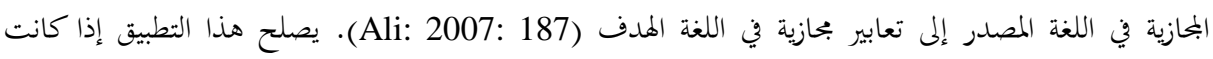

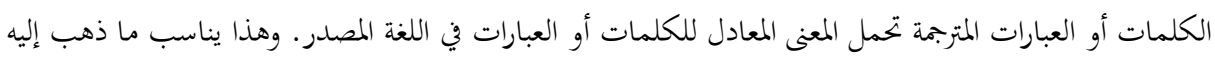

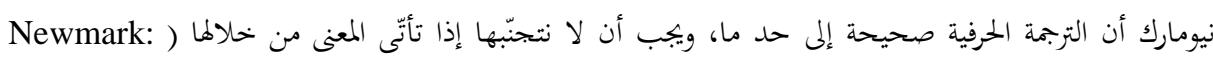
.(1988: 68-69

وبالنسبة إلى ترجمة الدلالات المحازية قد أشارت مونا باكير Mona Baker إلى أن المشكلات في ترجمة تلك التعابير تنبع من عدة أوجه، أولها: ليست لها تعابير اصطلاحية مكافئة في اللغة الهدف، وثانيها: لها تعابير

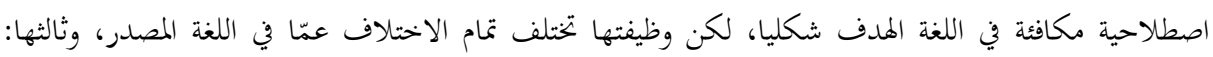
تحمل التعابير الاصطلاحية في اللغة المصدر المعنيين معا؛ المعنى الحرفي الأصلي والمعنى البمازي، ورابعها: تعيين السياق

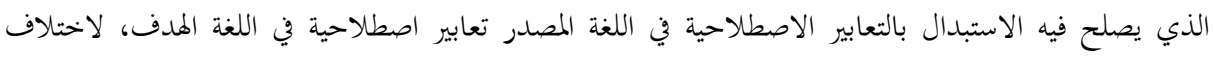
مدى إمكانية استخدامها بين اللغتين المصدر والهدف في سياق معين (Baker: 1992: 68-71).

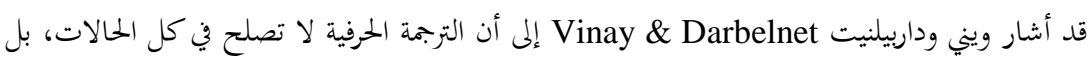

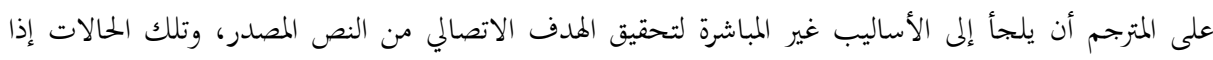

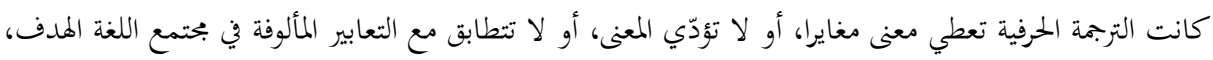

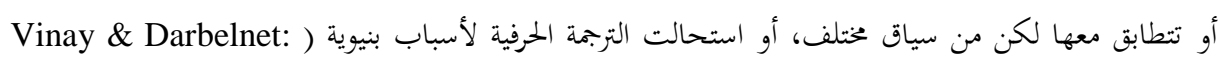

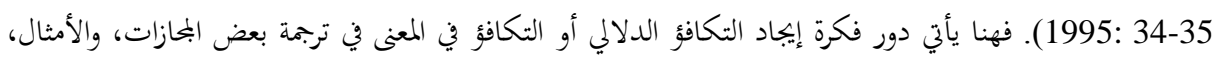

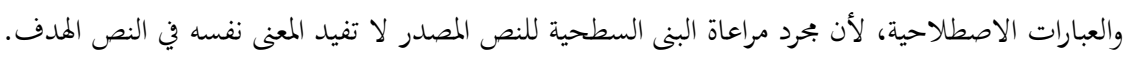

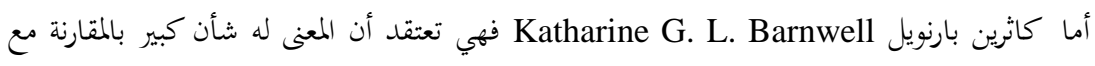

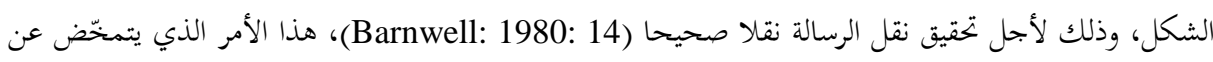

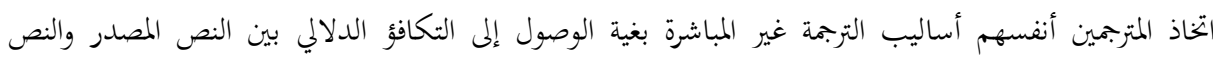


قد تطوّرت في الغرب نظرياتُ الترجمة العامة في القرن العشرين الميلادي، فبرزتْ منها بالفعل طرق مختلفة في الترجمة،

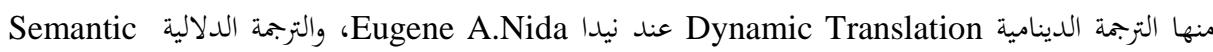
Translation كله، قد تناول بعضُ المنظرين الغربيين النظريةً الخاصة بترجمة المعاني المحازية.

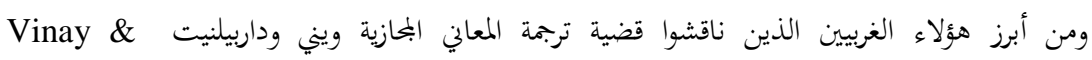
Darbelnet Raymond van Materina Reiss den Broeck

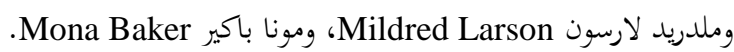
أما الأشخاص الذين تناولوا أسلوب ترجمة البحاز إلى التشبيه يوجين إيه. نيدا (Eugene A. Nida)،

وبيتر نيومارك (Peter Newmark)، وملدريد لارسون ( Mildred L. Larson).

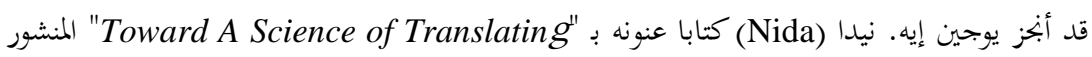

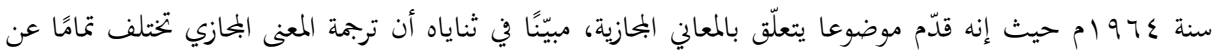

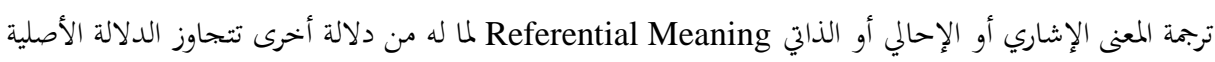

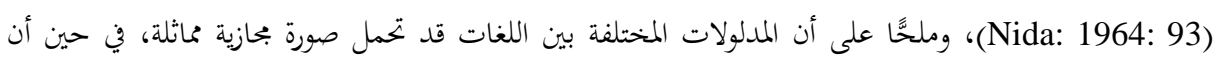

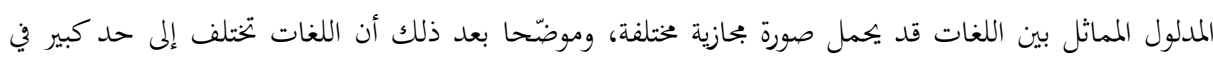
أساليب التعبيرات المحازية (Nida: 1964: 94).

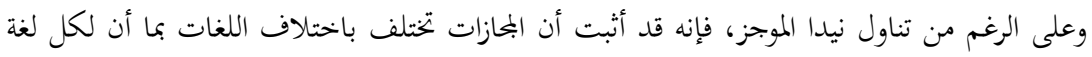

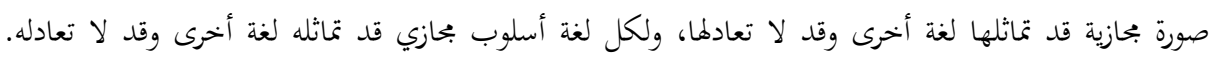

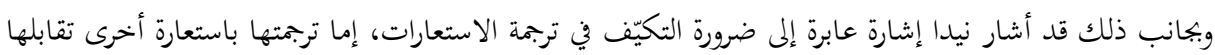

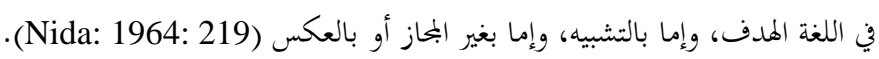

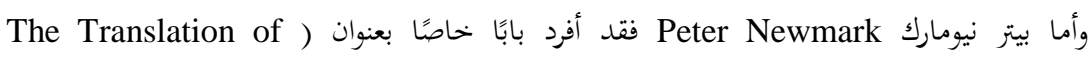
(Metaphor استراتيجيات التي يمكن الاستعانة بها في ترجمة الاستعارات بين اللغة الفرنسية والإنحليزية، وهي الإتيان بالاستعارة

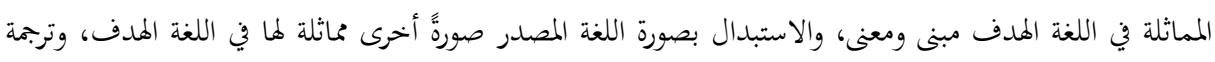
الاستعارة إلى التشبيه، وترجمة الاستعارة إلى اللغة الهدف ترجمة حرفية ومعنوية معا، وترجمة الاستعارة ترجمة معنوية،

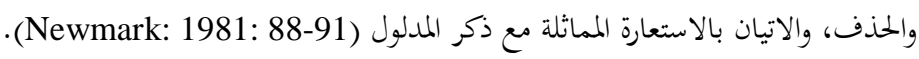

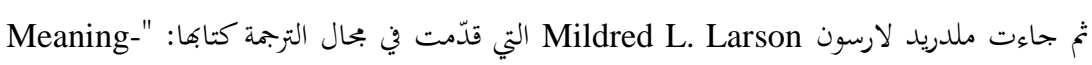
Based Translation: A Guide to Cross-Language Equivalence

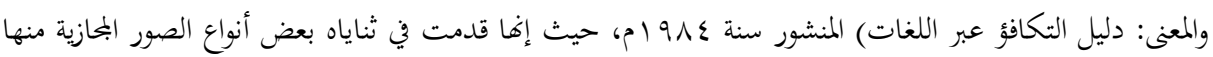




\section{Published by Faculty of Islamic Civilization Studies, KUIS}

الكناية (Metonymy)، والمحاز المرسل (Synecdoche)، والتعابير الاصطلاحية (Idioms)، والتلطيف

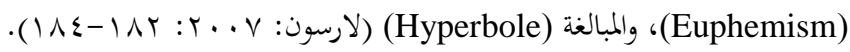

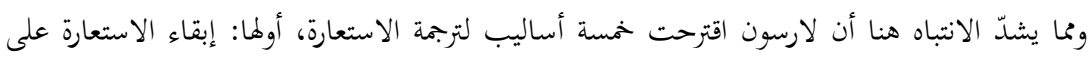

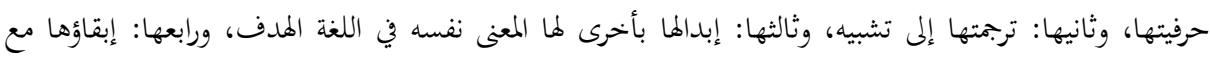

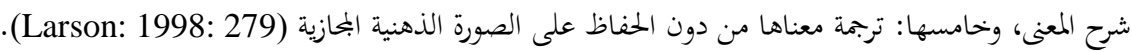

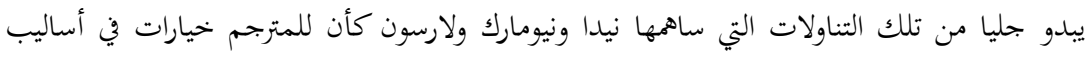

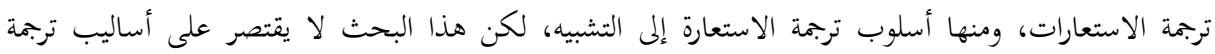

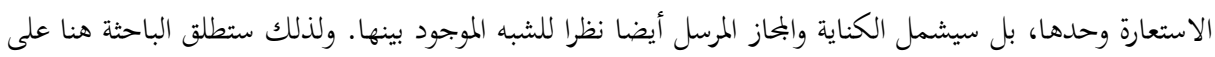

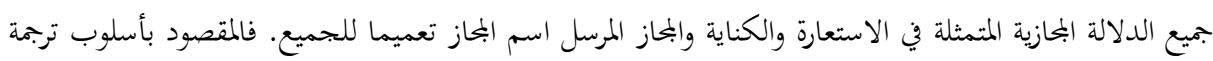

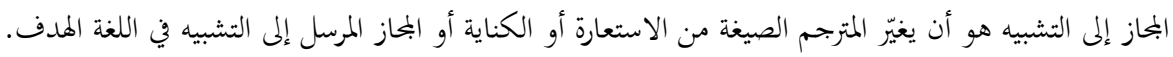

وجدير بالذكر هنا أن الباحثة تحلل النماذج التحليلية تحليلا سرديا، لا تحليلا إحصائيا، بغية الوصول إلى تحقيق مدى

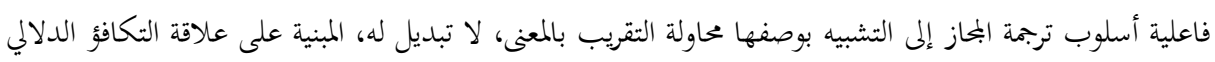

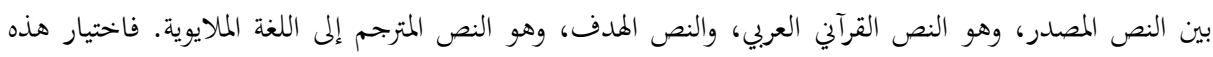

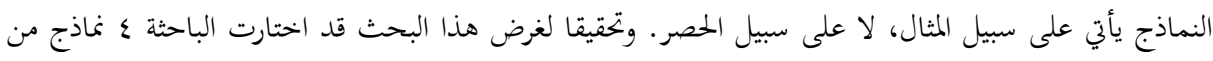

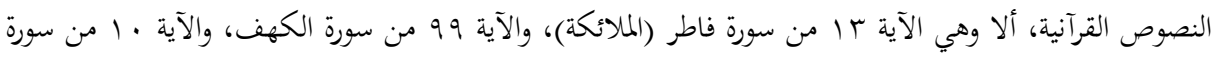

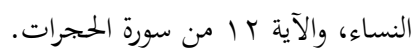

( V,1 المثال الأول: الآية سا من سورة فاطر (الملائكة)

لاحظت الباحثة أن ثمة مثالا واحدا يدلّ على اتفاق المترجمين على اتباع أسلوب ترجمة المحاز إلى التشبيه، ألا وهو

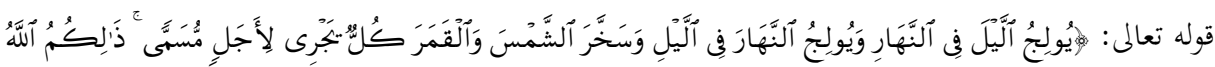

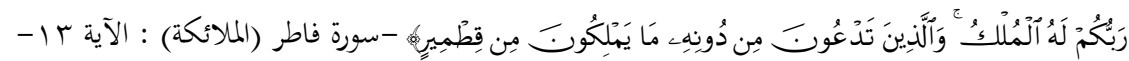
إن لفظ (قطمير) يعني "لفافة النواة، وهي القشرة الرقيقة الملتفة عليها"(الزخشري:

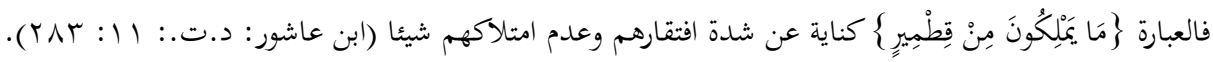

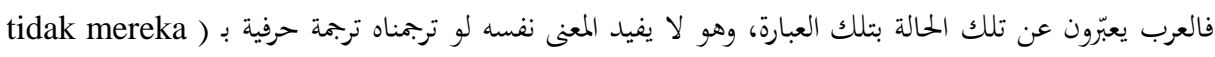
.(mempunyai dari selaput biji 


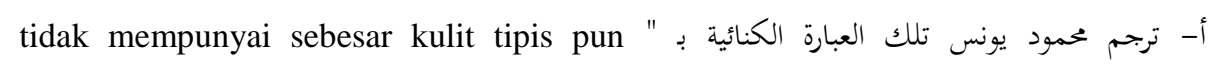

$$
\text { (sedikitpun). (الترجمة العكسية لها هي (لا يملكون مثل كبير قشرة رقيقة أيضا)). }
$$

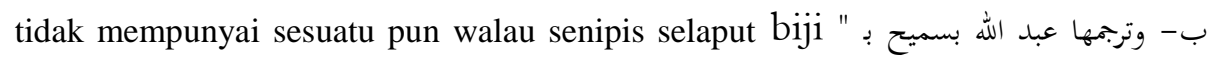
korma" (الترجمة العكسية لها هي (لا يملكون شيئا أيضا ولو كان مثل غشاء نواة التمر الرقيق)).

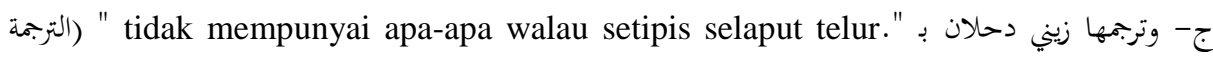
العكسية لما هي (لا يملكون شيئا ولو كان مثل فوف البيض الرقيق)).

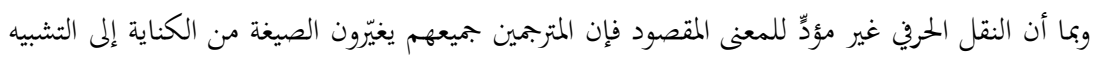

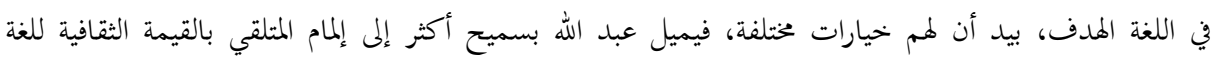

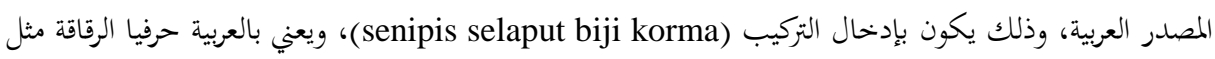

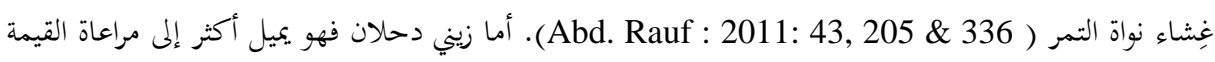
الثقافية للغة الهدف الملايوية، وذلك يكون بإدخال التركيب (Aetipis selaput telur)، ويعني بالعربية رقاقة تماثل

$$
\text { رقاقة غشاء البيض، تفسيرا للمعنى المراد من العبارة القرآنية (ما يملكون من قطمير). }
$$

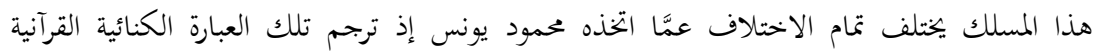

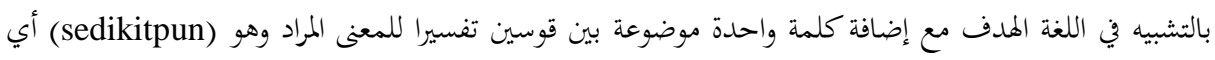
(ولو كان قليلا). من هذه الترجمات ترى الباحثة أن تلك الأساليب كلها صالحة للتداول والإفادة في البحتمع الملايوي

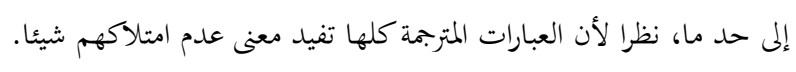

- V r المثال الثاني : الآية 99 من سورة الكهف

والشيء الذي يشدّ الانتباه هو أن الباحثة - من خلال النماذج المختارة - لا بحد التشابه بين المترجمَنْن في اختيار أسلوب ترجمة البحاز إلى التشبيه. غير أن الحاج زيني دحلان بمفرده قد غيّر الصيغة من الاستعارة إلى التشبيه في اللغة التهاه

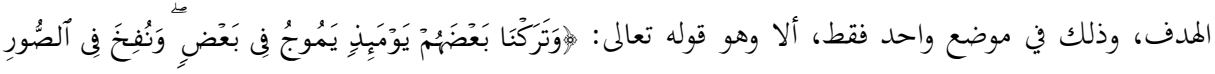

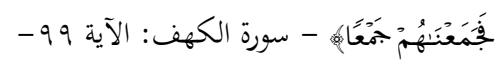

فاللفظ (ماج يموج) معجميًّ له معنيان، فالأول يعني ارتفع ماء البحر أو اضطربت أمواجه، والآخر يعني

اختلفت أمور القوم واضطربت (المعجم العربي الأساسي :

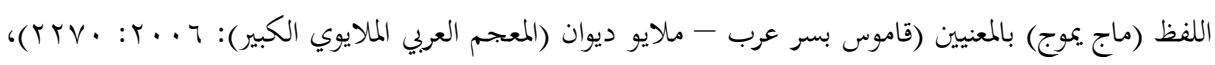

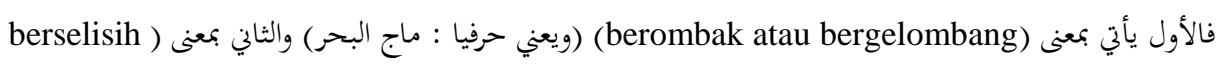
(faham dan kacau bilau

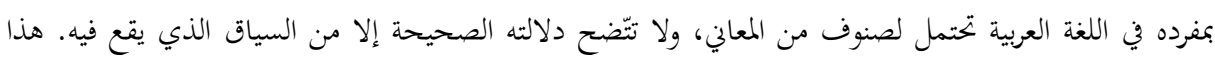
يعني أن بحرد النظر إلى مستوى اللفظ منفردا من الكلمات الأخرى لا ينتج المعنى الصحيح المراد به. 


\section{Published by Faculty of Islamic Civilization Studies, KUIS}

تبين لنا من خلال قوله تعالى أن الأسلوب البلاغي الوارد في السياق هو الذي يحدّد معنى الآية القرآنية،

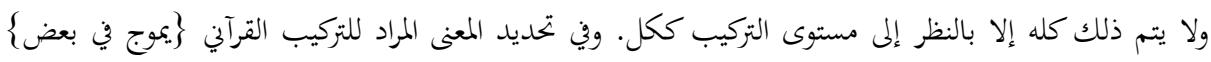

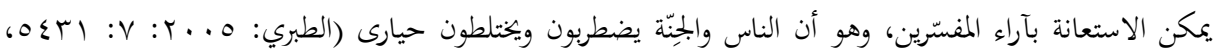

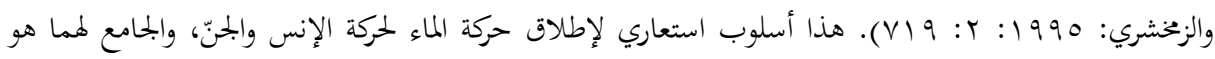

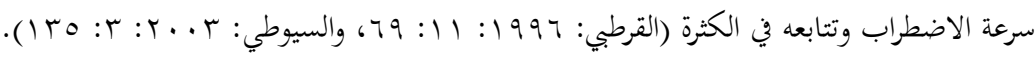
فيلحظ أن زيني دحلان يغيّر الصيغة من الاستعارة المكنية إلى التشبيه في اللغة الهدف، إذ يعبّر عن ذلك

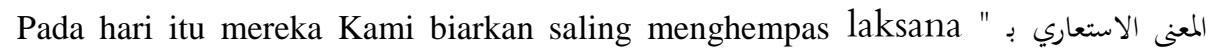
gelombang yang satu menimpa yang lain كالموج الذي يسقط البعض على البعض الآخر)). وعلى الرغم من أن أسلوب ترجمة المحاز إلى التشبيه من نادر

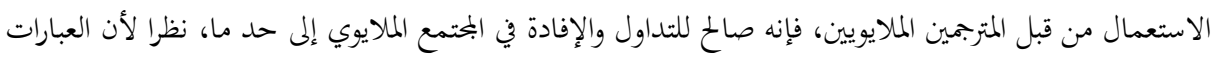
المترجمة كلها تفيد معنى سرعة الاضطراب وتتابعه في الكثرة. هذا خلاف لما اتخذه محمود يونس وعبد الله بسميح لأغما يلجآن إلى أسلوب الترجمة المعنوية، فترجم

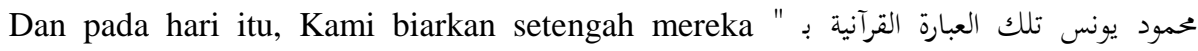
bercampur aduk dengan yang lain امتزاجا بالأخرين)، وترجمها عبد الله بسميح بـ " Dan Kami biarkan mereka pada hari itu (keluar beramai-ramai) bercampur-baur antara satu dengan yang lain

$$
\text { ونخن نتركهم في ذلك اليوم (يخرجون أفواجا) يمتزجون امتزاجا بين واحد بالأخرين). }
$$

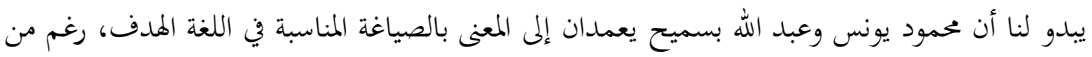

اختيارهما اللفظ المختلف، فالأول يأتي باللفظ (bercampur aduk)، والثاني بـ (bercampur-baur)، وكلاهما يعنيان حرفيا (يختلط أو يمتزج) مع اشتراك في الفعل معنى المبالغة. لكن الباحثة بحد كأن الختيار المتار اللفظين السابقين يؤدّيان إلى عدم وضوح الفكرة المقصودة نظرا لعدم وجود معنى الاضطراب والارتباك والحيرة فيهما كما فسّره المفسرون.

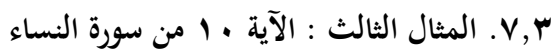

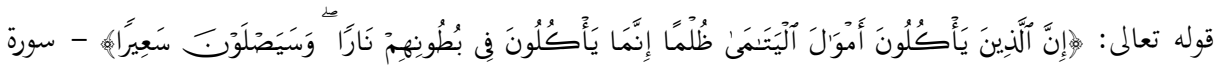

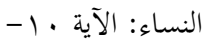

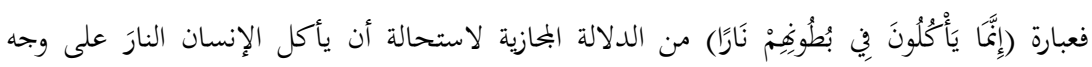

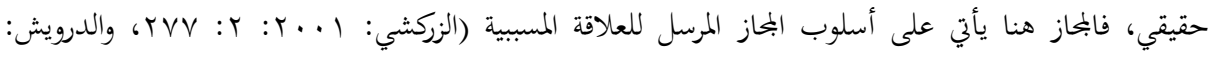

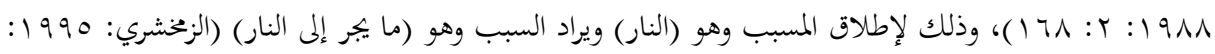

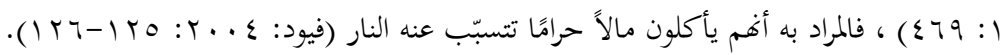
الترجمة والتعليق: 
أ- ترجم محمود يونس تلك الآية بـ " Sesungguhnya orang-orang yang memakan harta anak ."yatim dengan zalim, sebenarnya memakan api masuk perutnya

ب- وترجمها عبد الله بسميح بـ "Sesungguhnya orang-orang yang memakan harta anak-anak yatim secara zalim, sebenarnya mereka itu hanyalah menelan api ke dalam perut ." mereka

ج- جترجمها الحاج زيني دحلان بـ " Adapun orang-orang yang makan harta yatim dengan "sewenang-wenang, mereka itu telah menyimpan api di perutnya, يبدو جليا أن المترجمين كلهم يحتفظون بالألفاظ التي في الأصل حرفيا بدون توضيح المعنى المراد من النص المصدر، غير أن لمم خيارات مختلفة لبعض الألفاظ أو التركيب، حيث اتفقوا جميعهم على ترجمة اللفظ (يأكلون)

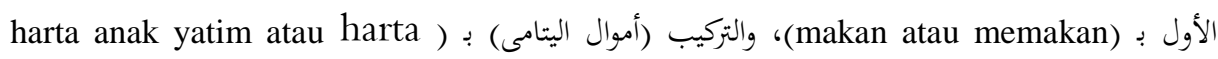

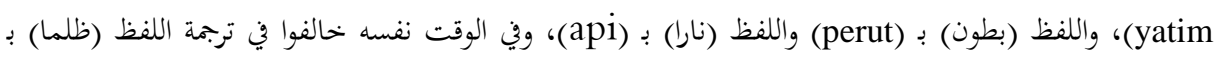

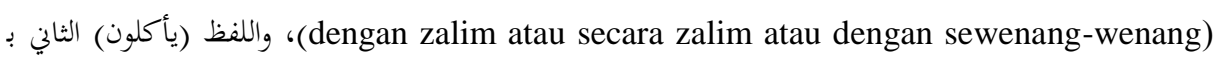
.(memakan atau menelan atau menyimpan) لاحظنا بصدد اللفظ (يأكلون) الثاني أن محمود يونس يختار اللفظ الأكثر حرفيا وهو (memakan)،

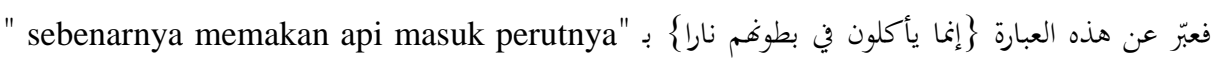

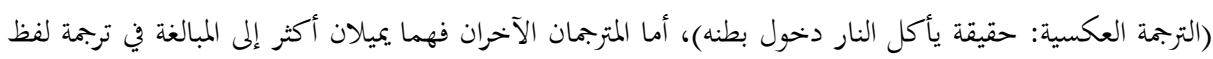
(يأكلون)، إذ يختار عبد الله بسميح لفظ (menelan)، ويعني حرفيا (يبلَع)، فعبر عنها بـ " sebenarnya mereka itu hanyalah menelan api ke dalam perut mereka يبلعون النار في داخل بطوهم)، أما الحاج زيني دحلان فهو اختار لفظ (menyimpan)، ويعني حرفيا (يدّخر)، فعبر عنها بـ "mereka itu telah menyimpan api di perutnya " الترجمة العكسية: هؤلاء يدّخرون النار في بطونه). والمهم هنا أفم كلهم يتركون للقراء تحديد المعنى المحازي بأنفسهم.

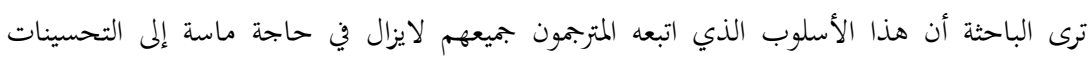

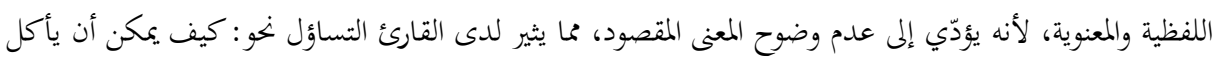

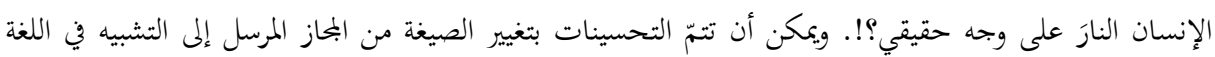

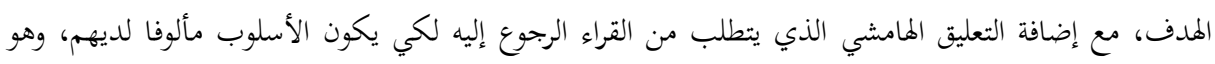

Sesungguhnya orang-orang yang memakan harta anak-anak yatim secara zalim, seolah-olahnya mereka itu memakan api ke dalam perut mereka*; dan mereka pula akan masuk ke dalam api nereka yang menyala-nyala.

* Ini adalah bentuk bahasa majaz atau kiasan yang cuba menggambarkan bahawa orang yang mengambil harta anak yatim secara tidak betul akibatnya nanti akan dimasukkan ke dalam api neraka kerana mereka memakan harta 
Published by Faculty of Islamic Civilization Studies, KUIS

فعسى أن إضافة اللفظ seolah-olahnya - الذي يعني بالعربية (كأنه) - سوف تساعد قراء الترجمات القرآنية على تصوير أن أكل الإنسان النار هنا لا يأتي على وجه حقيقي، بل هو تشبيه لحال الناس الذين يأكلون مالا حراما يتسبّب عنه دخول النار في يوم القيامة.

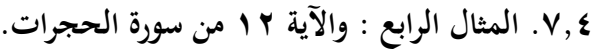

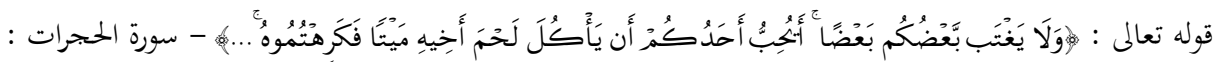

فسّر ابن عاشور (د.ت.: Y 1: ب00) هذه الآية قائلا: "فشبهت حالة اغتياب المسلم مَن هو أخوه في

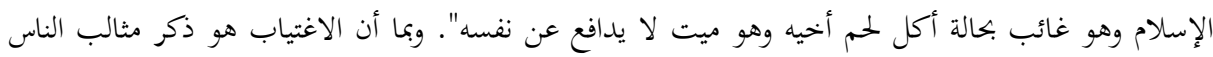

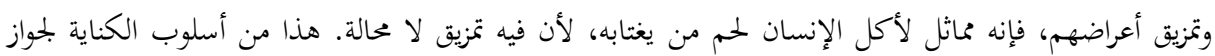
إرادة المعنى الأصلي.

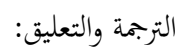

أ- ترجم محمود يونس تلك الآية القرآنية بـ " dan jangan pula setengah kamu mengumpat yang lain. Sukakah salah seorang kamu, bahawa dia memakan daging saudaranya yang .telah mati (bangkai)? Maka tentu kamu benci untuk memakannya. ب- ترجمها زيني دحلان بـ " dan jangan saling mengumpat; sukakah di antaramu makan ."daging saudara sendiri yang sudah mati, pasti kamu merasa jijik... يبدو لنا أغما احتفظا بالألفاظ التي في الأصل حرفيا محضا بدون استفسارات كأغما يتركان للقراء تحديد

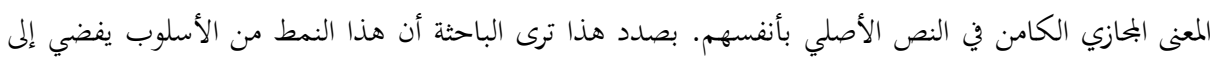
عدم وضوح الفكرة المقصودة. لذلك ترى الباحثة أن الأسلوب الذي اتخذه عبد الله بسميح يكون أفضل أسلوبيا وأكثر وضوحا بالمقارنة

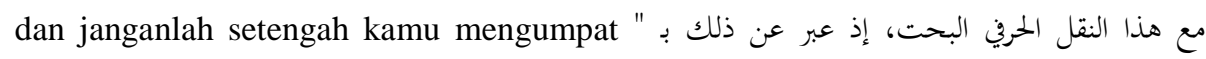
setengahnya yang lain. Adakah seseorang dari kamu suka memakan daging saudaranya yang telah mati? (Jika demikian keadaan mengumpat) maka sudah Jika demikian (tentu kamu jijik kepadanya... (keadaan mengumpat وبالإضافة إلى ذلك ترى الباحثة أننا يمكن أن نعبرّ عن تلك الدلالة البحازية الكنائية بتغيير الصيغة من

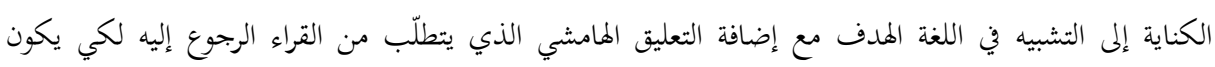
الأسلوب واضحا لديهم، فتلك الترجمة هي كما يأتي:

Dan janganlah setengah kamu mengumpat yang lain kerana perbuatan tersebut ibaratnya sama dengan seorang yang memakan mayat saudaranya yang telah mati. (Jika demikian perumpamaan keadaan mengumpat) maka sudah pasti kamu tidak suka dan merasa jijik...

Frasa (يأكر، لهم أخية) merupaka bentuk bahasa kiasan Arab yang cuba 


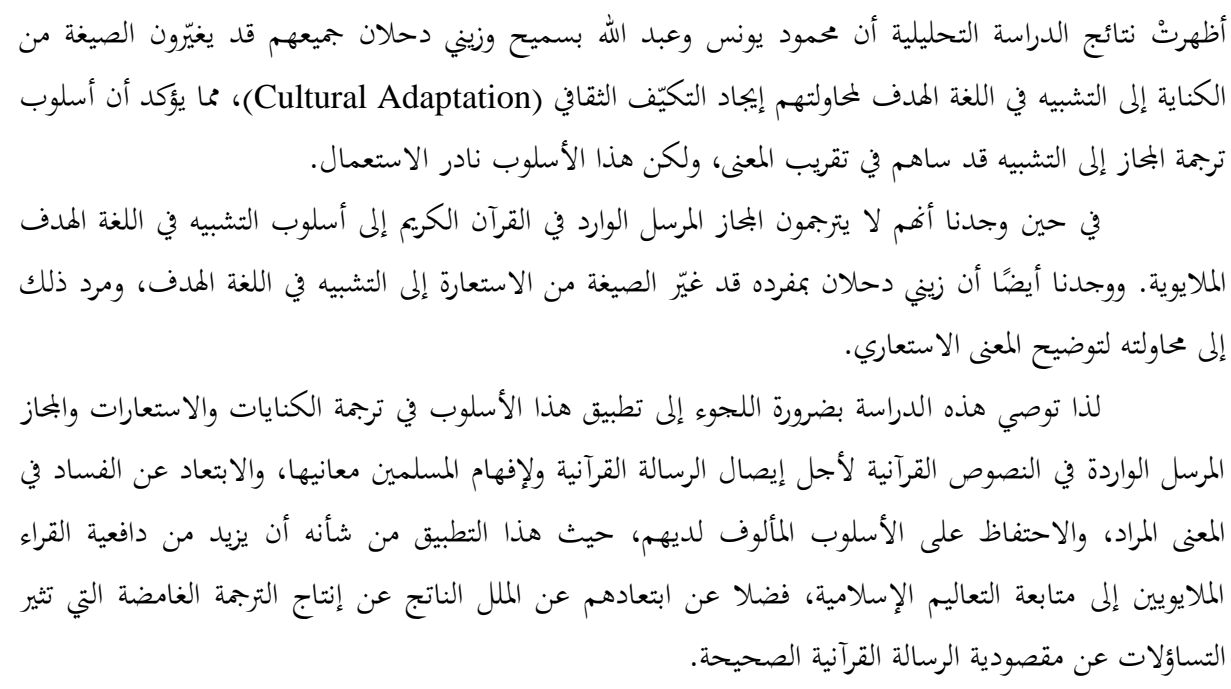

\section{References}

Al-Quran

(1999). al-Mu'jam al-Arabi al-Asasi. Al-Munazhamah al-Arabiyyah li al-Tarbiyyah wa al-Thaqafah wa al-Ulum.

(2006). Kamus Besar Arab - Melayu Dewan (al-Mu'jam al-Arabi alMalayuwiy al-Kabir). Kuala Lumpur: Dewan Bahasa dan Pustaka.

Abd. Rauf Dato' Haji Hassan, et, al. (2011). Kamus Bahasa Melayu-Bahasa Arab Bahasa Arab-Bahasa Melayu. Shah Alam Selangor: Oxford Fajar Sdn. Bhd. Edisi 2.

Ali, Abdul Sahib Mehdi. (2007). Encyclopedia Of Translation Terminology EnglishArabic. United Arab Emirates: College of Graduate Studies \& Research, University of Sharjah.

Anis, Ibrahim. (1991). Dalalah al-Alfaz. Egypt: Maktabah al-Anjelo al-Misriyyah.

Baker, Mona. (1992). In Other Words: A Coursebook on Translation. London \& New York: Routledge.

Barnwell, Katharine G. L. (1980). Introduction to Semantics and Translation. England: Summer Institute of Linguistics.

Bassnett-McGuire, Susan. (1988). Translation Studies. London \& New York: Routledge.

Al-Darwiish, Muhyi al-Din. (1988). I'raab al-Quran al-Karim wa Bayanuhu. Beirut: al-Yamamah wa Dar Ibn Kathir.

Fayyud, Basyuni 'Abd al-Fattah. (2004). 'Ilm al-Bayan: Dirasah Tahliliyyah limasail al-Bayan. Cairo: Muasasah al-Mukhtar.

Haydar, Farid 'Iwadh. (1999). 'Ilmu al-Dalalah dirasat nazariyyah wa tatbiqiyyah. Cairo: Maktabah al-Nahdhah al-Misriyyah. 
Published by Faculty of Islamic Civilization Studies, KUIS

Ibnu Jinni, Abu al-Fath Usman ibn Jinni. (n.d.). al-Khashaish. Tahqiq: Muhammad Ali al-Najjar. Egypt: Dar al-Kutub al-Misriyyah wa al-Maktabah al-Ilmiyyah.

Ibrahim, Majdi Ibrahim Muhammad. (2004). Buhuth wa Dirasat fi Ilmi al-Lughah (alSarf, al-Maajim, al-Dalaalah). Cairo, Egypt: Maktabah al-Nahdhah alMisriyyah,

Ibnu 'Aasyur, al-Syeikh Muhammad al-Zahir. (n.d.). Tafsir al-Tahrir wa al-Tanwir. Tunis: Dar Sahnun.

Ibn Qutaibah, Abu Muhammad Abdullah ibn Muslim. (1973). Ta'wil Musykil alQuran. Egypt: Dar al-Turath. $2^{\text {nd }}$. Edition.

Al-Jahiz, Abu Uthman 'Amr ibn Bahr. (1966). Al-Hayawaan. Volume 1 \& 5. Egypt: Maktabah wa Matba'ah Mustafa al-Baabi al-Halabi wa Aulaaduhu.

Al-Jurjani, al-Imam 'Abd al-Qahir. (1978). Asrar al-Balaghah fi 'Ilm al-Bayan. Beirut: Dar al-Makrifah.

Laasyin, 'Abdu al-Fatttah. (1998). Al-Bayan fi Dhaui Asaalib al-Quran. Beirut, Lebanon: Darul- Fikir al-'Arabi.

Larson, Mildred L. (1998). Meaning-Based Translation: A Guide to Cross-Language Equivalence. Lanham, New York, Oxford: University Press of America.

Larson, Mildred. (2007). Al-Tarjamah wa al-Makna: Dalil al-Takafu' 'Ibra alLughaat. Translated by Dr. Muhammad Muhammad Hilmi Halil. Universiti of Kuwait: Majlis al-Nasyri al-'Ilmi.

Newmark, Peter. (1988). A Textbook of Translation. New York, London, Toronto, Sydney, Tokyo, Singapore: Prentice Hall.

Newmark, Peter. (1981). Approaches To Translation. Oxford: Pergamon Press Ltd.

Nida, Eugene A.. (1964). Toward A Science of Translating: with special reference to principles and Procedures involved in bible translating. Leiden: E. J. Brill.

Al-Qurtubi, Abu 'Abdullah Muhammad ibn Ahmad al-Ansaari. (1996). Al-Jami' li Ahkam al-Quran. Cairo: Dar al-Hadith.

Rose, Marilyn Gaddis. (1981). Introduction: Time and Space in the Translation Process. in Translation Spectrum: Essays in Theory and Practice. edited by Marilyn Gaddis Rose. New York: State University of New York Press.

Al-Suyuti, Jalal al-Din Abdul Rahman. (2003). Al-Itqan fi 'Ulum al-Quran. Beirut, Lebanon: Al-Maktabah al-'Asriyyah.

Al-Tabari, Abu Jaafar Muhammad ibn Jarir. (2005). Jami' al-Bayan 'an Ta'wil Aayi al-Quran Tafsir al-Tabari. Cairo, Egypt: Dar al-Salaam.

Al-Tayyib, 'Iid Muhammad. (2007). Al-Mu'jamat al-Lughawiyyah wa Dalalat alAlfaz. Riyadh: Dar al-Zahra'.

Al-Tunaji, Muhammad. (1993). Al-Mu'jam al-Mufassal fi al-Adab. Beirut, Lebanon: Dar al-Kutub al-'Ilmiyyah.

Vinay, Jean-Paul, \& Darbelnet, Jean. (1995). Comparative Stylistics of French And English. translated by Juan C. Sager \& M.J. Hamel. Amsterdam/Philadelphia: John Benjamins Publishing Company.

Yaakob, Imiil Badi'. (2006). Mausu'ah 'Ulum al-Lughah al-Arabiyyah. Beirut, Lebanon: Dar al-Kutub al-'Ilmiyyah.

Al-Zamakhsyari, Abu al-Qasim Mahmud ibn Umar ibn Muhammad. (1995). AlKasyaf 'an Haqa'iq Ghawamidh al-Tanzil wa 'Uyun al-Aqawil fi Wujuh alTa'wil. Beirut, Lebanon: Dar al-Kutub al-'Ilmiyyah.

Al-Zarkasyi, al-Imam Badr al-Din Muhammad ibn Abdullah. (2001). Al-Burhan fi 'Ulum al-Quran. 


\section{BIOGRAFI PENULIS}

Nasimah binti Haji Abdullah, lulusan Doktor Falsafah dalam bidang Pengajian Linguistik Arab di Universiti Islam Antarabangsa Malaysia. Beliau mendapat ijazah Sarjana dalam bidang Pengajaran Bahasa Arab Sebagai Bahasa Kedua dari universiti yang sama dan Sarjana Muda dalam bidang Sains Kemanusiaan Dalam Bahasa dan Sastera Arab juga daripada universiti yang sama. Sekarang memegang jawatan sebagai Timbalan Dekan (Akademik dan Penyelidikan) di Fakulti Pengajian Peradaban Islam, Kolej Universiti Islam Antarabangsa Selangor (KUIS) dan merupakan pensyarah kanan di Jabatan Pengajian Bahasa dan Linguistik Arab. Penulisan akademik dan penyelidikan adalah dalam bidang linguistik Arab, pengajaran bahasa Arab sebagai bahasa kedua dan terjemahan Arab Melayu. Terlibat sebagai pakar rujuk untuk beberapa kursus pengajian Bahasa Arab di Universiti Terbuka Malaysia. Alamat e-mel: nasimah@kuis.edu.my. 